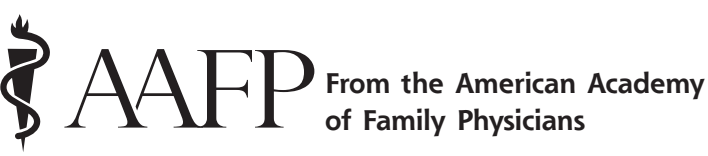

Ann Fam Med 2014;80. doi: 10.1370/afm.1610.

\section{BUILDING MORE MEDICAL SCHOOLS WON'T SOLVE PATIENT ACCESS ISSUES}

Although total US medical school enrollment increased nearly 23\% between 2000 and 2010, many of those newly minted physicians won't choose primary care specialties nor will they settle in states with the most severe primary care shortages. Those issues are discussed in a new study in the December issue of Academic Medicine.

According to study coauthor Andrew Bazemore, $\mathrm{MD}, \mathrm{MPH}$, director of the Robert Graham Center for Policy Studies in Family Medicine and Primary Care, the opening of more allopathic and osteopathic medical schools in the past decade was a direct response to widespread concerns about a US physician shortage. "We've seen an unbridled expansion of medical schools without anyone guiding or overseeing that overall expansion." says Bazemore.

In the study "State Patterns in Medical School Expansion 2000-2010: Variation, Discord and Policy Priorities," Bazemore and his coauthors note that the reality of budget constraints at the state and federal level, combined with calls for lower costs and more accountability in the health care system and in physician training, have added urgency to a growing problem.

"Despite evidence tying access to primary care physicians to improved community health outcomes and decreased costs, medical student interest in primary care and, thus, medical school output of primary care physicians, has been declining," say the researchers.

For the study, the researchers calculated population growth and medical school enrollment in individual states and examined the relationship between medical school expansion and states' needs. They wanted to know how many medical students return to practice in the states where they graduate and what states were successful in increasing their primary care workforces.

The authors knew from previous research that students who attend both medical school and residency training in the same state are more likely to remain in that state to practice medicine. They found that although $63 \%$ of medical students enter a medical school in their home state, only $39 \%$ of MD and
DO graduates who complete an out-of-state residency return to their home state to practice. This retention rate was higher (47\%) among students who attend public schools.

"Increasing medical school enrollment in states without sufficient GME (graduate medical education) positions and with medical student retention rates below the national median may not be a prudent investment," say researchers.

Bazemore says he was not surprised that the expansion of medical schools did not correlate at the state level with primary care population ratio measures of need.

"Some would say expansion of training in the United States is driven as much by market and political forces as it is by demonstrated population need and effective policymaking," says Bazemore.

He suggests that the research findings could be useful in conversations between family physicians and their state legislators - who are funding medical school expansion with state tax dollars-about how to direct and allocate state resources most effectively.

The research team also asks policy makers to - Look at local and regional health care needs and study population growth, access to care and the geographic distribution of physicians before making decisions about medical school expansion

- Consider replicating the coordinated training model used by the WWAMI (Washington, Wyoming, Alaska, Montana and Idaho) program in which neighboring states share resources with the University of Washington School of Medicine in Seattle

- Implement policies that encourage primary care at medical school preadmission, admission, and curriculum levels, and prioritize the admission of students "with known intentions and characteristics conducive to choosing primary care"

- Assess medical schools' success in turning out primary care physicians by following graduates 5 years after graduation.

Finally, the researchers call on state and federal stakeholders to learn from past mistakes, including the uneven manner in which medical school expansion occurred after warnings were raised a decade ago about physician shortages.

Sheri Porter

AAFP News Now 